\title{
FORMAÇÃO CONTÍNUA EM SERVIÇO: da construção crítica de um conceito à "reconcepção" da profissão docente
}

Valdeci Luiz Fontoura dos Santos (CPTL/UFMS)

\begin{abstract}
Resumo
Este artigo socializa parte dos resultados de minha pesquisa de mestrado em educação e apresenta, por meio de uma reflexão teórica, o conceito de formação contínua em serviço na tentativa de contribuir para o debate sobre formação de professores em nosso país. Para tanto, organizo este texto em três momentos: no primeiro, foco a compreensão possível sobre formação neste momento; no segundo, confronto as práticas de formação contínua com a teoria aqui eleita e, por fim, anuncio o conceito de formação contínua em serviço enquanto elemento fundante para a reconcepção da profissão docente.
\end{abstract}

Palavras-chave: Formação contínua. Reconcepção. Profissão docente.

\section{A Formação de Professores}

Ao pensar a formação dos professores, recorro a Garcia (1999) para inicialmente destacar a dimensão da formação enquanto processo, já que ele, a partir de Sharoon Feiman (1983), destaca quatro fases neste processo formativo específico:

\begin{abstract}
a) Fase de pré-treino (que) inclui as experiências prévias de ensino que os candidatos a professor viveram, geralmente como alunos, as quais podem ser assumidas de forma crítica e influenciar de um modo inconsciente o professor. b) Fase de formação inicial (que) é a etapa de preparação formal numa instituição específica de formação de professores, na qual o futuro professor adquire conhecimentos pedagógicos e de disciplinas acadêmicas, assim como realiza as práticas de ensino (Marcelo, 1989). c) Fase de iniciação (que) corresponde aos primeiros anos do exercício profissional do professor, durante os quais os docentes aprendem na prática, em geral através de estratégias de sobrevivência (Marcelo, 1991) d) Fase de formação permanente (que) é a última fase referida por Feiman, e inclui todas as atividades planificadas pelas instituições ou até pelos próprios professores de modo a permitir o desenvolvimento profissional e aperfeiçoamento de seu ensino (GARCIA, 1999, p. 25-26).
\end{abstract}

Pacheco e Flores (1999) referem-se também à proposição de Feiman caracterizando, assim, três grandes etapas formativas: inicial (pré-serviço), iniciação e a formação contínua. Destacam eles que Feiman acrescenta uma fase prévia a essas três, por ela designada de préformação, que comportaria "[...] o conjunto de experiências e representações que o candidato a professor possui e que poderão influenciar, de forma (in)consciente, ao longo do seu percurso formativo, e concretamente, na sua prática profissional" (PACHECO e FLORES, 1999, p. 52).

\begin{tabular}{|l|l|l|l|l|l|}
\hline Interface da Educ. & Paranaíba & v. 1 & n. 1 & p. 5-19 & 2010 \\
\hline
\end{tabular}


Tal categorização permite, além de aferir ao conceito de formação de professores, a ideia de continuidade, estabelecer fases para que se possa entender a formação, para além da continuidade, enquanto um processo muito peculiar quando se pensa a formação dos professores.

A partir do referido teórico pode-se mapear, provisoriamente, a seguinte conceitualização: é possível perceber que existe forte relação entre as experiências dos professores enquanto alunos, sua formação inicial e as diversas modalidades de formação contínua a que venham a ter acesso em suas trajetórias profissionais; que dada à natureza do trabalho docente, dar-se-á ad eternum, caracterizando assim, um processo de formação ininterrupto, ainda mais se considerarmos que o próprio exercício da docência implica aprendizagem para os professores, pois, como negar que também se aprende a ser professor o sendo?

Ressalve-se ainda que não há como garantir mecanicamente o avanço de uma fase para outra, a exemplo são todos os estudantes que não vieram a ingressar na fase de formação inicial posto que não optaram pela docência, ou ainda, os professores que se comportam como professores iniciantes, mesmo no fim de suas carreiras, por não terem adentrado à fase da formação permanente, que implicaria em uma outra relação com a profissão docente, se considerarmos o desenvolvimento profissional também como um processo.

Além disso, e de acordo com o "perfil dos professores brasileiros" (UNESCO, 2004), $53 \%$ deles ingressam na carreira antes da obtenção da titulação mínima exigida.

A formação de professores, ainda para Garcia, pode ser entendida como a

[...] área de conhecimentos, investigação e de propostas teóricas e práticas que, no âmbito da Didática e da Organização Escolar, estuda os processos através dos quais os professores - em formação ou em exercício - se implicam individualmente ou em equipa, em experiências da aprendizagem através das quais adquirem ou melhoram seus conhecimentos, competências e disposições, e que lhes permite intervir profissionalmente no desenvolvimento do seu ensino, do currículo e da escola, com o objectivo de melhorar a qualidade da educação que os alunos recebem (GARCIA, 1999, p. 26).

Nesse sentido, por "formação de professores" pode-se compreender um processo contínuo de aprendizagens que toma como mote as diversas temáticas da profissão docente que didaticamente podem ser organizadas em três grandes dimensões: saber, saber-fazer e saber-ser.

Dentro desse processo contínuo, encontram-se duas grandes categorias: a Formação Inicial e a Formação Contínua, que são diretamente marcadas pelos processos de auto/hetero/inter-formação e também pelas teorias de formação formal, categorial, dialogística e

\begin{tabular}{|l|c|c|c|c|c|}
\hline Interface da Educ. & Paranaíba & v. 1 & n. 1 & p. 5-19 & 2010 \\
\hline
\end{tabular}


técnica; sabendo-se que, à medida que a confluência entre elas privilegie uma ou outra combinação, implicarão em distinções tanto teóricas quanto práticas, principalmente na modalidade da formação contínua.

Tais combinações não parecem estar encerradas definitivamente em uma única possibilidade, mas parecem se diferenciar também pelo que poderia chamar de protagonismo dos sujeitos nelas envolvidos.

A formação contínua que diretamente emana das agências formadoras parece não ser equivalente às práticas formativas das agências empregadoras e vice-versa. Caberia, porém, perguntar: todas as práticas de formação contínua emanadas das agências formadoras e empregadoras são de formação contínua em serviço?

Antes de responder a essa questão, faz-se necessário destacar que a formação contínua encerra em sua natureza duas ideias principais: "uma de mudança para novos saberes directamente relacionados com a prática profissional; outra de atividades conducentes a uma nova compreensão do fazer didáctico e do contexto educativo" (PACHECO, 1995, p.120).

Além disto, Howey citado por Pacheco (1995, p. 120) distingue na formação contínua

[...] seis dimensões principais: desenvolvimento pedagógico, conhecimento e compreensão de si mesmo, desenvolvimento cognitivo, desenvolvimento teórico, desenvolvimento profissional pela investigação e desenvolvimento na carreira, através de adopção de novos e variados papéis docentes.

Dessas dimensões, parece que o desenvolvimento profissional pela investigação/pesquisa abarcaria, mesmo que indiretamente, todas as outras dimensões e poderia realizar-se a partir dos paradigmas formativos que são o paradigma da deficiência, o paradigma do crescimento, o paradigma da mudança e, por fim, o paradigma de solução de problemas.

Desses paradigmas, e considerando a singularidade do ato educativo, interessa, para discutir a formação contínua em serviço, o paradigma de solução de problemas por apontar a atividade docente como um conjunto de novas situações e, por extensão, sujeita à ocorrência de fatos inusitados e não repetitivos que possivelmente não foram abarcados na formação inicial dos professores; concordando aqui com a propositura de uma trilogia da formação contínua que produza a vida, a profissão e a escola (NÓVOA, 2002).

Cabe chamar a atenção para o fato de que, ao manter e desenvolver o ensino, as agências empregadoras deveriam respeitar as duas dimensões da profissão docente - ensinar e aprender -, ao contrário de explorar o ensino em detrimento da aprendizagem contínua dos professores. A

\begin{tabular}{|l|c|c|c|c|c|}
\hline Interface da Educ. & Paranaíba & v. 1 & n. 1 & p. 5-19 & 2010 \\
\hline
\end{tabular}


partir dessa inferência, parece que muitos sistemas ofertam programas de formação contínua que de serviço sustentam apenas o rótulo, já que são programas para professores que se encontram em exercício, muitas vezes reproduzindo a organização da formação inicial no que se refere à verticalidade entre formadores e professores.

Avançando nessa discussão, as práticas formativas organizadas em cursos modulares fora do horário de trabalho dos professores não seriam formação contínua em serviço, mas sim, mera reprodução de práticas formativas desenvolvidas pelas agências formadoras, que em suas manifestações organizadas pelas agências empregadoras poderiam ser entendidas com base no paradigma da deficiência, de inspiração clássica, que coloca como mote da formação contínua, a atualização ou reciclagem das aprendizagens realizadas na formação inicial.

Cabe, ainda, sobre formação de professores, assumir que a formação inicial sem a formação contínua, ou ainda essa última sem a primeira, não dão conta de responder às necessidades formativas dos professores. O que também torna os esforços investidos na formação dos professores (inicial e contínua) fundamentais para que, por meio da reflexão sobre sua prática, seja alcançado seu desenvolvimento profissional na perspectiva de que nessa reflexão se organize e se edifique ainda mais o conhecimento dos professores nas suas mais variadas dimensões.

A formação contínua é um fenômeno em escala mundial e não se refere somente à formação de professores. Na verdade, sua ênfase recai sobre a colocação profissional dos trabalhadores em geral. Na França, a temática é abordada a partir da visão da sociologia enquanto objeto de estudo focado na inserção profissional dos trabalhadores em um cenário no qual se coloca a "crise da empregabilidade" como problema a ser superado.

Dubar (2000) faz um recorte na realidade francesa e a compara com os outros países da Comunidade Européia, analisando historicamente o fenômeno da formação profissional contínua, destacando o surgimento de políticas de formação contínua na França com a instauração de um verdadeiro "sistema de formação contínua" como meio para vencer a exclusão dos trabalhadores do mundo do trabalho, datando dos anos 70 do século passado.

É possível perceber em Dubar que a formação profissional contínua adquire um objetivo claro de fomento à inclusão profissional tanto dos jovens trabalhadores quanto de outros trabalhadores que se encontram excluídos do mundo do trabalho. Ao fazer a tensão comparativa entre a França e outros países europeus, Dubar discute as ações

\begin{tabular}{|l|c|c|c|c|c|}
\hline Interface da Educ. & Paranaíba & v. 1 & n. 1 & p. 5-19 & 2010 \\
\hline
\end{tabular}


públicas, privadas e sindicais de atuação na área de formação contínua, enfatizando as sindicais tanto na perspectiva de formação como acesso a melhores salários (ou até a manutenção do posto de trabalho), quanto na formação, como elemento de organização dos trabalhadores. Destaca, ainda, que a mobilização sindical na França envolve inclusive a reivindicação por recursos para serem usados especificamente na formação contínua dos profissionais.

Apesar de Dubar não conceituar o que viria a ser formação profissional contínua objetivamente, ele destaca a ação pública por meio das preocupações da Fédération de l'Éducation Nationale que apontam para a necessidade do estabelecimento de um vínculo entre a formação inicial e a contínua por meio da proposição de um grand service public de l'education permanente, enquanto prioridade.

O aspecto mais interessante da discussão de Dubar encontra-se no relato da obrigatoriedade legal a que têm sido submetidas as agências empregadoras no destino e uso de percentuais pecuniários para a formação contínua de seus funcionários, fato que poderia sinalizar para uma diferenciação entre essas ações e outras no cenário da formação contínua por remeter especificamente aos que se encontram no exercício da profissão.

Interessa destacar o 'aparato' legal que orienta as ações na área de formação contínua na realidade francesa e que também se apresenta, neste caso, especificamente, aos professores, nas realidades portuguesa e italiana. Nos dois últimos casos, é possível encontrar dispositivos legais que, de uma forma ou de outra, delineiam a formação contínua dos professores. Nesse aspecto, a realidade portuguesa parece mais interessante por apresentar a formação contínua regulamentada por meio do "Estatuto da Carreira dos Educadores da Infância e dos Professores dos Ensinos Básico e Secundário" e garantida pela "Lei de Bases do Sistema Educativo" que em seu artigo $35^{\circ}$ define que:

1. A todos os educadores, professores e outros profissionais da educação é reconhecido o direito à formação contínua.

2. A formação contínua deve ser suficientemente diversificada de modo a assegurar o complemento, aprofundamento e actualização de conhecimentos e de competências profissionais, bem como a possibilitar a mobilidade e a progressão na carreira.

3. A formação contínua é assegurada predominantemente pelas respectivas instituições de formação inicial, em estreita cooperação com os estabelecimentos onde os educadores e professores trabalham. 4. Serão atribuídos aos docentes períodos especialmente destinados à formação contínua. (LEMOS e CARVALHO, 2000, p. 232).

Interface da Educ.

\begin{abstract}
v. 1
\end{abstract}
ก. 1

Paranaíba

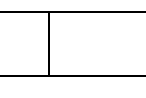

2010 
O ordenamento jurídico da formação dos professores portugueses tem como objetivo principal, segundo Pacheco (1995, p. 120):

[...] melhorar a competência profissional dos docentes nos vários domínios de sua actividade; incentivar os docentes a participar ativamente na inovação educacional e na melhoria da qualidade da educação e do ensino; adquirir novas competências relativas à especialização exigida pela diferenciação e modernização do sistema educativo.

A experiência italiana aponta para a educação contínua em seu sistema de ensino, mas merece maior destaque a reflexão que a academia italiana vem tecendo, segundo Guasti (1986), no sentido de se pensar sobre a instituição de um sistema de formação em serviço dos professores que supere o sistema vigente nos anos 80 de formação dos professores italianos.

No primeiro artigo do livro organizado por ele, Calidoni cita Howey, para assim definir formação em serviço

[...] in sintesi, la FIS/CS puó essere definita come l'insieme di quelle attivitá di formazione continua focalizzatta sull'interesse, i bisogni, i problemi direttamente connessi con il ruolo e le responsabilitá degli operatori in uns especifica sede scolastica. (HOWEY apud GUASTI, 1986, p. 18).

Tal conceito aponta para o processo de formação a que devem ter acesso os professores que já se encontram em exercício profissional nas escolas, dando margem a entendê-lo assim, como um recorte no conceito maior: formação contínua.

No Brasil, a discussão sobre a formação contínua de professores toma corpo efetivamente no âmbito da academia conectada à questão da formação inicial e, progressivamente, tem avançado para o recorte e estudo da formação contínua, sabendo-se que esta última, e segundo Mizukami (2002, p. 28):

[...] busca novos caminhos de desenvolvimento, deixando de ser reciclagem, como preconizava o modelo clássico, para tratar de problemas educacionais por meio de um trabalho de reflexividade sobre as práticas pedagógicas e de uma permanente (re)construção da identidade docente.

Nesse sentido, é possível afirmar que muitas já são as produções sobre a formação contínua, entretanto, no cenário legal, a garantia do acesso à formação contínua encontra-se, apenas turvamente garantida nos Incisos II e V do artigo 67 a Lei 9.394/96:

Art. 67 - Os sistemas de ensino promovem a valorização dos profissionais da educação, assegurando-lhes, nos termos dos estatutos e dos planos de carreira do magistério público: I - ingresso exclusivamente por concurso público de provas e títulos; II aperfeiçoamento profissional continuado, inclusive com licenciamento periódico remunerado para esse fim; III - piso salarial profissional; IV - progressão funcional baseada na titulação ou habilitação, e na avaliação do desempenho; V - período

\begin{tabular}{|l|c|c|c|c|c|}
\hline Interface da Educ. & Paranaíba & v. 1 & n. 1 & p. 5-19 & 2010 \\
\hline
\end{tabular}


reservado a estudos, planejamento e avaliação, incluído na carga de trabalho; VI condições adequadas de trabalho.

Além do problema de centralizar a temática da formação contínua na dimensão do saberfazer, para não dizer que se trata de um reducionismo técnico, a LDB delega a cada sistema de ensino, tanto a definição do que seria a formação contínua, quanto a garantia e as formas de acesso a essa etapa do desenvolvimento profissional dos professores.

Concilie-se a isso, ainda, o reducionismo técnico da concepção de formação contínua presente no texto da Lei 9394/96, que mais parece um "eco" re-significado da racionalização do ensino. Entretanto, não há como negar que existe neste país uma garantia legal, que confrontada com o passado, apresenta-se como que inusitada.

A realidade brasileira, diferentemente das realidades portuguesa e italiana, principalmente, ensaia a instituição e regulamentação legal da formação contínua, que em alguns aspectos parece equivocada.

A garantia legal de acesso à formação contínua, nessas quatro realidades, não deve ser entendida como concessão, mas sim como resultado da mobilização dos profissionais, das agências formadoras e de pesquisa, e também das organizações representativas dos professores, na busca por melhores condições tanto de trabalho quanto de formação.

Essa teia teórico-prática, enquanto cenário, pode conduzir ao fato de que formação contínua se faria institucionalmente, com o necessário estabelecimento de uma política de qualificação dos diversos profissionais, com ênfase na reflexão dos professores sobre sua própria formação.

Afirma-se institucionalmente, chamando aqui a atenção para o papel dos sistemas de ensino, que, enquanto agências que empregam os professores da educação básica, deveriam ter um sério compromisso com a formação contínua.

Ao contrário disso, tem-se assistido à instituição de uma verdadeira indústria de formação contínua, pois colocada como elemento unicamente de progressão na carreira dos professores, notadamente os brasileiros, transforma-os em clientes e não em sujeitos da formação contínua.

Dubar (1996), citado por Canário (2000, p. 90), explicita que esse aspecto da oferta da formação contínua

Trata-se, no fim de contas de tornar o indivíduo responsável pela sua própria formação, pela sua inserção, mesmo pelo seu despedimento. $\mathrm{O}$ título de alguns grandes programas de formação 'a empresa de si' diz claramente que cada um deve gerir-se a si próprio

\begin{tabular}{|l|c|c|c|c|c|}
\hline Interface da Educ. & Paranaíba & v. 1 & n. 1 & p. 5-19 & 2010 \\
\hline
\end{tabular}


como uma empresa (...). Cada um deve ter consigo próprio a relação de um empresário com o seu produto, procurar 'vender-se', negociar o 'capital' em que se tornou.

Isto sinaliza para o "descompromisso" das agências empregadoras dos professores com a formação contínua, vislumbrada como uma estratégia de mercado, pois coloca sobre os professores não só a responsabilidade de gerir sua própria formação, mas também de fazê-lo para garantir seu trabalho, o que demonstra, portanto, que não se concebe a formação contínua como elemento efetivo da constituição da carreira docente, mas sim, e segundo a lógica mercantil, como um up grade muito comum no meio empresarial, no qual a formação contínua resume-se a um bem simbólico.

\section{As Manifestações das práticas de formação contínua e o confronto com a teoria: desvelando o fenômeno}

Diante da complexidade do fenômeno em que consiste a formação e a formação de professores, destacam-se as práticas de formação contínua destinadas aos professores em exercício.

Tal tipo de formação parece inserir-se primeiramente na confluência entre as fases de iniciação e de formação permanente (FEIMAN apud GARCIA, 1999), mas todos aqueles que venceram a etapa da formação inicial também são sujeitos de práticas de formação contínua, mesmo que não tenham ainda ingressado na carreira docente.

Caberia então uma distinção em favor de práticas formativas que se destinem aos professores em exercício, efetivamente, o que poderia sinalizar para a possibilidade de mais de uma modalidade de práticas em formação contínua. O que está posto é que a formação contínua destina-se àqueles que já possuem a formação inicial ofertada pelas agências formadoras.

Seguindo a linha de raciocínio estabelecida até aqui, vale tentar alinhavar as práticas de formação contínua a que temos notícia e também acesso no Brasil, combinando-as aos modelos de auto/hetero/inter-formação (DEBESSE apud GARCIA, 1999), cruzados com as teorias de formação formal, categorial, dialogística e técnica (MENZE apud GARCIA, 1999), na tentativa de melhor compreender esse fenômeno.

A partir do protagonismo dos atores envolvidos no fenômeno em que se constitui hoje a formação contínua, esboça-se, esquematicamente, tanto as áreas em que existiriam protagonismos independentes e também as áreas em que existiria interdependência.

\begin{tabular}{|l|l|l|l|l|l|}
\hline Interface da Educ. & Paranaíba & v. 1 & n. 1 & p. 5-19 & 2010 \\
\hline
\end{tabular}


É possível perceber que as várias práticas de formação contínua não se encerram definitivamente em uma mesma modalidade, já que se diferenciam inicialmente pelo protagonismo, tanto de seus propositores quanto de seus sujeitos.

Como exemplo, é possível citar a diferença entre os objetivos que uma agência formadora estabelece ao criar e manter um programa de Pós-Graduação e os objetivos de uma Secretaria de Educação, que institui uma Oficina Pedagógica. Entretanto, e para além de uma simples diferenciação, vale se entregar ao desafio de discriminar as práticas de formação contínua implementadas pelas agências formadoras das práticas implementadas pelas agências empregadoras, destacando a formação contínua em serviço.

As agências formadoras comprometidas com o desenvolvimento intelectual dos professores, apostam na implementação de Programas de Pós-Graduação com o fim de ofertar a possibilidade de formação contínua aos que já venceram as barreiras da formação inicial, independentemente de estarem ou não em exercício. Temos aqui uma pista de que essa formação, não obrigatória, depende essencialmente da iniciativa da agência formadora, posto que os professores poderiam, diante de suas necessidades e nível de organização, no muito solicitar a instituição de Programas de Pós-Graduação junto às IES e nunca às Agências que os empregam, uma vez que as mesmas não são Instituições formadoras na concepção legal que, no presente, levamos a cabo.

Considerando isso, as práticas de formação contínua que podem ser desenvolvidas junto aos Programas de Pós-Graduação nas agências formadoras, não se dão em serviço, inclusive pressupõem o afastamento das atividades profissionais dos que nelas ingressam por meio das agências de fomento à pesquisa e por meio de bolsas de ajuda de custo.

Aliada a essa constatação, apresenta-se, ainda, outro elemento que pode auxiliar nessa conceituação: as agências formadoras, mesmo comprometidas que estão com a formação contínua dos professores, não são responsáveis diretas pelo desenvolvimento profissional desses, na medida em que eles não são seus funcionários e permanecem ligados aos Programas de Pósgraduação até a conclusão de seus cursos, fato que dificulta o estabelecimento, com elas, de uma relação de continuidade existencial e profissional.

Cabe explicitar que a formação de professores se dá em um contínuo processo permanente, e objetiva melhorar as atividades de ensino dos professores, está claro também, que tal profissão tem imbricadas duas grandes dimensões: ensinar e aprender.

\begin{tabular}{|l|l|l|l|l|l|}
\hline Interface da Educ. & Paranaíba & v. 1 & n. 1 & p. 5-19 & 2010 \\
\hline
\end{tabular}


Ao manter e desenvolver o ensino, as agências empregadoras deveriam considerar que a docência possui essas duas dimensões. Uma delas já consagrada: ensinar, dar aulas, conduzindo o processo de aprendizagem dos estudantes, e outra: continuar aprendendo. Ao contrário disso, as condições de trabalho da maioria dos professores brasileiros exploram a dimensão do ensinar em detrimento da dimensão do continuar aprendendo. Há que se mencionar que, ao dar suas aulas, o professor está automaticamente imerso em um processo de aprendizagem, mas, para além da empiria, é preciso discutir a instituição da aprendizagem enquanto elemento constitutivo da profissão docente.

\section{Formação Contínua em Serviço: Anúncio de um Conceito}

As práticas formativas organizadas em cursos modulares fora do horário de trabalho dos professores não podem ser consideradas como formação contínua em serviço, posto que estão fora da jornada de trabalho dos professores, consistindo assim, em mera reprodução das práticas formativas desenvolvidas pelas agências formadoras, sem o necessário envolvimento histórico dessas últimas com a formação em si.

É possível entender, então, por formação contínua em serviço, as práticas formativas que as agências empregadoras levariam a cabo com a necessária reorganização da estrutura do trabalho docente, contemplando tanto a dimensão do ensinar quanto a dimensão do aprender.

Um programa de formação contínua, para ser considerado como de formação contínua em serviço, precisa estar contemplado dentro da jornada de trabalho do professor, evitando assim, a responsabilização unicamente dos professores pela continuidade de sua formação (enquanto clientes), tomando para si, enquanto agência responsável pela manutenção e desenvolvimento do ensino, o compromisso de possibilitar a formação contínua em serviço.

O que parece ser perceptível é o fato de que a formação contínua está sendo instituída, mas não como elemento constitutivo da concepção da carreira docente, como já mencionado neste capítulo, mas sim, como uma corrida em busca de ínfimos acréscimos salariais por meio da progressão na carreira.

Os compromissos das agências empregadoras com os professores têm que ir além das práticas já cristalizadas de mera certificação em cursos pontuais e descontínuos ainda mais se for assumido que hoje em dia

\begin{tabular}{|l|l|l|l|l|l|}
\hline Interface da Educ. & Paranaíba & v. 1 & n. 1 & p. 5-19 & 2010 \\
\hline
\end{tabular}


[...] os professores não são apenas consumidores, mas também produtores de materiais de ensino; que os professores não são apenas executores, mas também criadores e inventores de instrumentos pedagógicos; que os professores não são apenas técnicos, mas são também profissionais críticos e reflexivos (NÓVOA, 2002, p. 36).

Assim, o acesso à formação contínua é um direito dos professores brasileiros que estão em exercício, mas, diante da trajetória histórica e incipiente consolidação de um sistema nacional de educação, não constitui efetivamente um dever para as agências que empregam os professores, o que denota que ainda concebemos a profissão vinculada ao ensinar apenas posto que a carreira e as jornadas de trabalho ainda não contemplam o aprender dos professores.

O estudo deste objeto, por meio da análise de um programa de formação contínua inserida na jornada de trabalho dos professores, possibilita um avanço conceitual, cumprindo assim com o chamamento de Cachapuz, pois enuncia um novo quadro teórico de referência.

É fato que

[...] as perspectivas de formação presentes nas políticas educativas e nas práticas são o resultado de diferentes paradigmas, embora os professores valorizem a sua formação mais pelo paradigma da deficiência do que pelos paradigmas do crescimento, da mudança e da resolução de problemas (PACHECO e FLORES, 1999, p. 131).

Entretanto, independente da significação que se dá à formação contínua, por parte dos professores, já parece ser consenso a sua necessidade, tanto no que se refere à instituição de uma escola de qualidade quanto na perspectiva da consolidação da profissão docente.

Junto a isso, parece que a Lei de Diretrizes e Bases da Educação Nacional (9.304/96), em seu artigo 67, ao colocar que cada sistema de ensino deverá regulamentar a forma de acesso à formação contínua no Brasil, regula de forma mui incipiente o acesso à formação contínua dos professores brasileiros.

Tal fato tem feito surgir uma verdadeira indústria de formação contínua que assedia e seduz inúmeras secretarias de ensino em nosso país com verdadeiros "pacotes" de formação contínua, que de "em serviço" ostentam apenas o adjetivo, posto que se destinam aos professores em exercício.

A Formação contínua em serviço enquanto uma das modalidades da formação contínua deve ser um compromisso dos sistemas de ensino para o enfrentamento da universalização de uma escola que atenda tanto às necessidades quanto às expectativas das camadas populares, que, para além da visão de ascensão social, possibilite às gerações mais jovens a efetiva compreensão do mundo em que vivem.

\begin{tabular}{|l|l|l|l|l|l|}
\hline Interface da Educ. & Paranaíba & v. 1 & n. 1 & p. 5-19 & 2010 \\
\hline
\end{tabular}


É claro que tal proposição assume uma posição que coloca mais à esquerda este movimento de pensamento. Digo isto, pois considero aqui o papel dos sistemas de ensino, notadamente os públicos, imprescindível no que se refere à edificação de uma profissionalização docente digna e condizente com o papel da escola, re-concebendo assim a profissão.

Se, e de acordo com Teodoro (2003, p. 44),

[...] nas últimas duas décadas do século XX, assistiu-se à lenta mas segura afirmação de um novo bloco social hegemónico que tem vindo a impor um novo senso comum as políticas públicas de educação, assente uma redução dos conceitos de democracia às práticas de consumo, de cidadania a um individualismo possessivo,

a formação contínua é concebida, nesta lógica, como um investimento pessoal pois resume-se a um bem de consumo. Pensar a formação contínua em serviço enquanto elemento constitutivo da carreira docente estaria, no mínimo, na contra mão do senso comum estabelecido.

Assim, faz-se necessário assumir que a instituição da formação contínua em serviço seria notadamente um compromisso, que por meio de uma política educativa, instituir-se-ia na confluência de elementos formativos de três ordens: $a$. as de ordem individual; $b$. as de ordem coletiva; e, c. as de ordem sistêmica.

As necessidades formativas, de ordem individual, referem-se às condições objetivas de acesso a e permanência na etapa da formação contínua, considerando-se, para tal, a pessoa do professor e seu meio, o que perpassa tanto sua condição econômica para, por exemplo, comprar livros, até suas condições psicológicas, quando consegue se perceber enquanto ser em formação.

As de ordem coletiva referem-se à dimensão profissional do professor na confluência das suas condições de trabalho e de interação com o lócus do seu ofício: a escola. Refiro-me aqui ao engajamento profissional que tem como elemento os vínculos pessoais e profissionais que o professor estabelece no seu trabalho, tanto interna quanto externamente, se for considerado que a escola é um dos cenários no qual a pessoa do professor se insere.

E, por sua vez, as de ordem sistêmica encontram-se na tensão entre o anunciado enquanto profissionalização docente e as frentes de luta dos professores brasileiros em diversas instâncias entre as quais se destaca a sindical. Além disso, tal ordem está inserida na esfera dos direitos trabalhistas dos professores em um contexto em que se responsabiliza a escola por uma crise de ordem muito mais complexa que enfrenta o capitalismo real.

$\mathrm{Na}$ tensão dessas três ordens de fatores, não cabe conceber a formação contínua em serviço como sinônimo de formação contínua, posto que essa última caracteriza-se como um

\begin{tabular}{|l|l|l|l|l|l|}
\hline Interface da Educ. & Paranaíba & v. 1 & n. 1 & p. 5-19 & 2010 \\
\hline
\end{tabular}


grande "guarda-chuva", que abarca dentro de si inúmeras possibilidades de organização e implementação de modalidades formativas dos professores. Mas recortando dela uma modalidade inerente à responsabilidade de um sistema de ensino, destaco, como alternativa a formação contínua em serviço, que, se elevada especificamente como modalidade, pode servir para o delineamento de uma carta de princípios para a formação contínua destinada aos professores que se encontram no exercício da profissão.

$\mathrm{Na}$ tentativa de contribuir para a discussão e possível articulação, em nosso país, de políticas de formação contínua que enfrentem os desafios colocados hoje ao magistério brasileiro, afirmo que a formação contínua em serviço, instituir-se-ia na garantia de:

a) Redefinição objetiva das dimensões da docência enquanto profissão, considerando-se para tanto, horas para especificamente ensinar e horas especificamente para continuar aprendendo implicando assim na reconcepção da profissão docente;

b) Instituição de setores destinados à formação contínua nos sistemas de ensino, edificando-se assim, uma rede de formadores que pertença ao sistema articulados com as agências formadoras;

c) Reorganização do lócus de trabalho do professor com a instituição de políticas de aquisição e manutenção de acervo bibliográfico para os docentes, e;

d) Construção coletiva dos programas de formação contínua em serviço, na mediação entre as necessidades dos professores e as necessidades do sistema, tendo a produção teóricocientífica como elemento mediador deste processo.

Inspiro-me no conceito de formação em serviço de Howey (apud GUASTI, 1986), buscando conceituar a formação contínua em serviço ao definir sua condição (em serviço) e seu dimensionamento (ordens pessoal, coletiva e sistêmica), o que tornaria os aspectos elencados acima como constitutivos para o estabelecimento dessa modalidade formativa. A mesma pode ser imprescindível para que os professores em exercício venham a galgar um efetivo estágio de formação permanente, sem o que, pensar em uma escola que dê conta dos desafios colocados a ela hoje, pode não passar de uma falácia que oculta um projeto vil e pernicioso que não comunga efetivamente com a busca necessária por igualdade e justiça social.

Para finalizar, faço das palavras de Nóvoa (2002, p. 66) as minhas, pois

[...] o debate aí está. Uma vez mais (...) num desses momentos raros na vida das profissões em que sentimos que vários frutos são possíveis: o modo como a concebermos, mas sobretudo o modo como a praticarmos, vai ajudar a construir um

\begin{tabular}{|l|c|c|c|c|c|}
\hline Interface da Educ. & Paranaíba & v. 1 & n. 1 & p. 5-19 & 2010 \\
\hline
\end{tabular}


desses futuros. Porque qualquer projecto de formação transporta uma 'utopia', que não é a imagem do impossível, mas a introdução no presente de uma outra maneira de pensar e de viver a educação,

que torna possível e necessário o compromisso dos educadores com a reconcepção da profissão docente contribuindo assim para que condições dignas de ensinar e aprender se estabeleçam em nossas escolas.

\section{Referências Bibliográficas}

BRASIL. Lei de diretrizes e bases da educacional nacional. Lei ${ }^{\circ} 9.394$, de 20 de dezembro de 1996. Diário Oficial da União, Brasília, Distrito Federal, 23 dez.1996.

CACHAPUZ, A. F. Do que temos, do que podemos ter e temos direito a ter na formação de professores: em defesa de uma formação em contexto. In: BARBOSA, R. L. L. (Org.). Formação de educadores: desafios e perspectivas. São Paulo: Editora UNESP, 2003.

CANÁRIO, R. Educação de adultos: um campo e uma problemática. Lisboa: Educa, 2000.

DUBAR, C. La formation professionnelle continue. 4. ed. Paris: La Découverte, 2000.

GARCIA, C. M. Formação de professores para uma mudança educativa. Porto: Porto Editora, 1999.

GUASTI, L. Il sistema della formazione in servizio dei docenti. II. Ed. Itália: Editrice La Scuola, 1986.

LEMOS, J. E CARVALHO, L. G. Estatuto e estrutura da carreira docente: legislação anotada. Porto: Porto Editora, 1999.

MIZUKAMI, M. da G. N. et al. Escola e aprendizagem da docência: processos de investigação e formação. São Carlos: EdUFSCar, 2002.

NÓVOA, A. A formação de professores e trabalho pedagógico. Lisboa: Educa, 2002.

PACHECO, J. A. Formação de professores: teoria e práxis. Portugal: Universidade do Minho, 1995.

PACHECO, J. A. e FLORES, M. A. Formação e avaliação de professores. Porto-Portugal: Porto Editora, 1999.

TEODORO, A. É possível uma política de educação à esquerda? Uma reflexão sobre possibilidade e esperança na acção política. Revista Lusófona de Educação, Lisboa, n. 02, p. 43 $51,2003$.

\begin{tabular}{|l|l|l|l|l|l|}
\hline Interface da Educ. & Paranaíba & v. 1 & n. 1 & p. 5-19 & 2010 \\
\hline
\end{tabular}


UNESCO. O perfil dos professores brasileiros: o que fazem, o que pensam, o que almejam. São Paulo: Moderna, 2004. 